\title{
The Doors Exist
}

\author{
Fyodor A. Lukyanov
}

DOI: $10.31278 / 1810-6374-2020-18-2-5-8$

The work on this issue will be remembered for a long time. But not because of social distancing we got stuck with in the spring of 2020 , just like most people around the world, although it has intensified the feeling of unreality. Our mind is torn between opposites.

The freewheeling (not to say "carefree") lifestyle of the last fifteen to twenty years-a time period negligible in historical terms-at some point started to be taken as natural and irreversible. And it is hard to believe that the pandemic has most likely drawn a line under it. On the one hand, the media compete in warnings about an imminent economic recession comparable to the Great Depression and a possible end of universal mobility achieved by the third decade of the 21st century. On the other hand, all the signs of material culture created in the era of liberal globalization are still with us, at arm's length. Advertisements keep inviting us to travel, and tempting offers urge us to hurry up with lucrative investments. It seems that the quarantine gloom is about to dissipate, and life will go back to normal. Yet the truly unprecedented scale of the COVID-19 epidemic, attacking the entire world at the same time, leaves no hope that it will pass without consequences for humanity.

The situation makes it difficult to maintain refined wisdom and predict future changes impartially, especially as no one can tell for sure what exactly the changes will be. Glib commentators and "public intellectuals" immediately jumped at predictions lying on the surface even though it was already clear that the pandemic was no more than the tip of the iceberg or even a misleading pseudo reality.

When the initial tide of "the world will never be the same!" prophecies subsided, most assessments of world politics became more conservative. Indeed, force majeure did not disrupt the global agenda, it only exacerbated existing trends. The epidemic has rationalized what many thought was a reckless devi- 
ation from a reasonable order. The rise of nationalism, the rejection of dogmatic universalism, the creeping fragmentation of the world economy, calls for abandoning the liberal economic model so that the state could play a bigger role (in one form or another), intensifying all-round competition between major countries, primarily the United States and China... COVID-19 has made all of this either necessary (the only way to fight infection is isolation) or inevitable. And now the question is not what path humankind will take but where the limits are if it goes along this path.

Yet far more affected by the pandemic will be relations between society and the state. Instruments of control and surveillance, which were already being introduced most rapidly in step with technological progress, have received a powerful boost. Just like after the $9 / 11$ attacks, there is growing demand for security through control, but it is much more pronounced now. Mass readiness to accept the state of emergency as a norm emasculates the previously heated debates on the collision of democracy and authoritarianism. As technology improves, their methods become practically identical. Moreover, the pluralistic model appears to be even more traumatic in terms of individual rights than the centralized one, because it makes personal data available not only to the state, but also to private corporations. And manipulation becomes more sophisticated and multilayered, turning the very notion of democracy into sham.

It is also true, however, that the same technologies give citizens and societies new opportunities to influence the state, making it harder for the latter to block them without throwing its own tools into question. This hybrid between classical utopia and dystopia creates a new form of feedback whose evolution will determine the social and political future of the world.

During the last "pre-coronavirus" forum in Davos held at the end of January 2020, two issues stood out practically in all presentations: the reverse side of digitalization and climate change as a form of relations between the Earth (nature) and humankind. For the latter issue, the crisis has also served as a catalyst, which is only natural-any epidemic combines natural and human factors. The unfortunate pangolin, whose eating in the Hubei province allegedly triggered the coronavirus' triumphant march across the globe, will go down in history as a symbol of fatal symbiosis. The environmental issue, which has been gaining momentum since the beginning of this century, is getting a second wind, too. Especially since, at first glance, it has the potential for international cooperation, the 
deficit of which has been constantly grumbled about lately. There is a risk, though, that it will be so only at first glance: the climate agenda, often addressed with a hefty share of aggression, may turn into yet another weapon in the new situation.

As for Russia, the pandemic caught it at the crossing. Shortly before the infection spilled over China's borders to ravage the world, Russia stepped on the road of tuning its Constitution and modifying the state system for the coming period. Technically, nothing has been canceled, just put on hold due to unforeseen circumstances. But the political plans developed by the end of 2019 need at least some adjustment because too much has changed in the outside world, and the public mood inside the country has also shifted. Just like everywhere else, the pandemic did not smash down the existing agenda in Russia, but simply accentuated piled-up multidirectional developments. It was clear even without unexpected upheavals that an important stage had come to an end in Russian politics. It can be assessed differently, but one thing is unquestionable: the goals and means (external and internal) remained in logical harmony throughout this period. Now harmony is gone, and the search for a new balance will proceed in completely different conditions.

The most impressionable commentators say that history will be divided into "before" and "after," as always happened after world wars. Perhaps, they are right. Thank God, the point at issue is not the scale of destruction (at least for now), but the feeling that it is time to turn the page. "Humanity feels the urgent need to close the doors," renowned Russian writer Yevgeny Vodolazkin wrote recently. "This does not mean that the doors will now be nailed down. Not at all, they are just closed to be opened again. What matters is the memory that the doors exist." This memory will hardly remain forever, but surely for a long time. 